\title{
7 - A cultura de notificação de incidentes
}

\author{
Celsa Raquel Villaverde Melgarejo \\ Patricia de Carvalho Mastroianni \\ Fabiana Rossi Varallo
}

\section{SciELO Books / SciELO Livros / SciELO Libros}

MELGAREJO, C. R. V., MASTROIANNI, P. C., and VARALLO, F. R. A cultura de notificação de incidentes. In: Promoção da cultura de notificação de incidentes em saúde [online]. São Paulo: Editora UNESP, 2019,pp. 37-40. ISBN: ISBN: 978-85-9546-337-0.

https://doi.org/10.7476/9788595463370.0009.

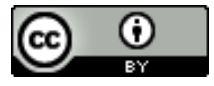

All the contents of this work, except where otherwise noted, is licensed under a $\underline{\text { Creative Commons Attribution } 4.0 \text { International license. }}$

Todo o conteúdo deste trabalho, exceto quando houver ressalva, é publicado sob a licença Creative Commons Atribição 4.0.

Todo el contenido de esta obra, excepto donde se indique lo contrario, está bajo licencia de la licencia Creative Commons Reconocimento 4.0. 


\section{7 \\ A CULTURA DE NOTIFICAÇÃO DE INCIDENTES}

A cultura de notificação requer um compromisso organizacional em que deve haver preparo e encorajamento para realizar a notificação de eventos ou quase-eventos, estabelecendo um ambiente propício a receber e avaliar as notificações sem punições (Reason, 2000). O processo de notificação, a própria cultura de notificação, é considerado um dos quatro atributos que fazem parte da cultura de segurança. Os demais atributos referem-se à aprendizagem, flexibilidade e a uma cultura justa (Flemons; McRae, 2012).

A flexibilidade é a capacidade da instituição de saúde se reconfigurar diante de determinados perigos. É saber lidar com erros e propor soluções adequadas. $\mathrm{O}$ aprendizado se dá a partir desses erros, em que se concentra a etapa da avaliação de dados de segurança e o desenvolvimento de estratégias efetivas para minimizá-los (Flemons; McRae, 2012). Uma cultura de aprendizagem se manifesta não somente quando ocorrem erros, pode-se também aprender com o sucesso. É importante o envolvimento de líderes de equipe capazes de difundir e perpetuar a consciência de segurança entre todos os funcionários e profissionais da saúde da instituição. À medida que há amadurecimento da cultura de segurança hospitalar, a cultura de aprendizagem e de notificação deixará de ser reativa, tornando-se proativa, no sentido de identificar possíveis falhas, previr atos 
inseguros e propor melhorias para a segurança da instituição como um todo (Blake et al., 2006).

Em razão da grande demanda nos serviços de saúde e a gama diversificada de profissionais que atuam nesse meio, há a necessidade de coordenação eficaz na atenção à saúde a partir da colaboração da equipe multiprofissional. As profissões envolvidas no cuidado à saúde necessitam de capacitações e treinamentos constantes para desenvolver atitudes, conhecimentos e habilidades que fortaleçam atos seguros e de qualidade (Reeves, 2016).

A instituição de saúde deve orientar constantemente seus profissionais a respeito da importância da notificação, bem como fazê-lo de forma assertiva no que se refere à qualidade do relato (preenchimento completo de todos os campos solicitados), além de fornecer instrumentos adequados (formulários simples, de fácil entendimento e preenchimento), de modo que a notificação seja totalmente inserida na prática da cultura de segurança (Bezerra et al., 2009; Franco et al., 2010; Françolin et al., 2015; Gama et al., 2016; Reis; Laguardia; Martins, 2012).

A notificação proporciona incentivo aos profissionais de saúde a se tornarem responsáveis pelos seus atos ou pelos de sua equipe, promovendo mais vigilância com os cuidados na saúde, permitindo melhorias e assegurando benefícios não só ao paciente mas também ao colaborador (Sammer et al., 2010).

A cultura justa está inserida na cultura de segurança a partir do momento que se cria um ambiente de confiança para que as notificações de incidentes ocorram como um hábito, com pessoas motivadas a notificarem os eventos, porém com a consciência do que é aceitável ou não. Além disso, a cultura justa visa reconhecer os erros como falhas no sistema e não falhas individuais, embora não se exima a responsabilidade do profissional em manter boa conduta ou ser responsável pelos seus atos (Sammer et al., 2010). Para tanto, recomenda-se que a instituição garanta o anonimato e o voluntariado não só no momento de notificar algum incidente, mas também no ato de dar uma devolutiva ao profissional de saúde para que não seja punitiva, afetando-o de maneira negativa e 
impactando os fluxos de atendimento e organizacional de saúde (Mira et al., 2013).

O conhecimento de fatores (ambientais, organizacionais, individuais, de equipe, do paciente, de tarefa) que possam contribuir para a ocorrência do evento adverso é o que determina a segurança do sistema como um todo, pois somente por meio desses fatores é que pode ser realizada a avaliação dos pontos críticos relativos à assistência à saúde, propondo melhorias pontuais para cada caso. Uma cultura de qualidade se faz necessária como uma política institucional em todas as fases do cuidado do paciente a partir da inclusão, da colaboração e de corresponsabilidades das diversas equipes multidisciplinares.

Além da cultura justa e não punitiva, estudos na literatura apontam itens essenciais para promover a segurança do paciente, sendo a presença de profissionais com capacidade de liderança uma das peças fundamentais. Aliados à educação em saúde, profissionais líderes poderão proporcionar segurança, de modo a "gerenciar" toda a sua equipe com foco na resolução e prevenção de problemas, propondo estratégias e barreiras relacionadas aos incidentes (Blake et al., 2006). Uma das medidas propostas pelo National Quality Forum (NQF), a partir de sua atualização em 2006, é focar em estruturas e sistemas de liderança para melhorar a segurança do paciente.

Um sistema de saúde que tenha profissionais qualificados e com capacidade de liderança poderá desenvolver melhor um trabalho em equipe. Este é outro ponto essencial, pois, cada vez mais, as instituições deparam com pacientes complexos, tanto no que diz respeito ao curso da doença quanto aos fatores pessoais, em que a cobrança de resultados acaba se tornando por vezes desconfortável. Portanto, o suporte entre profissionais para promoção da rápida recuperação e minimização de falhas, além de um ambiente favorável ao respeito mútuo e de confiança, podem influenciar na segurança do paciente (Sammer et al., 2010).

A comunicação faz parte da liderança e do trabalho em equipe, é o elo entre os profissionais em uma instituição de saúde. Portanto, a adoção de uma linguagem clara e acessível a todos é uma técnica que fortalece o cuidado à saúde, principalmente no que se refere aos 
cuidadores e familiares que não são da área da saúde, a estes deve-se garantir que a orientação recebida esteja adequada.

Uma maneira de assegurar que os cuidadores entenderam o que lhes foi dito é pedir para que expliquem com suas próprias palavras as informações que lhes foram passadas, tanto com ralação ao tratamento como para algum procedimento (Meyer et al., 2010).

A dupla ou tripla conferência em todas as fases do cuidado ao paciente fazem parte de uma boa comunicação entre equipes e minimiza erros em cadeia. A elaboração e a adoção de checklist, protocolos, guidelines (diretrizes), procedimentos padronizados e uniformizados a partir de evidências científicas tornam a prática assistencial mais bem-sucedida, principalmente quando há a presença de líderes capazes de fomentar a utilização desses recursos, tornando o processo de aprendizado contínuo, haja vista a ampla atualização desses instrumentos (Sammer et al., 2010).

Portanto, uma instituição deve ser composta por líderes para garantir que haja sensibilização sobre as falhas no desempenho da equipe, orientando a corresponsabilidade sobre essas lacunas e melhorando o desempenho de habilidades, garantindo, assim, ações seguras para uma adequada assistência ao paciente (Meyer et al., 2010).

Uma instituição que valorize seus pacientes e familiares, no sentido de acolher suas decisões e vontades, tornando-os participativos no processo do cuidado, cria um ambiente favorável para discussões de casos levando a uma ação mais segura, proporcionando o processo de cura durante a hospitalização e a promoção do bem-estar como uma linha de cuidado contínua. A visão que se tem de uma instituição de saúde é o relato de seus pacientes acerca do processo de cuidado. Isto é, a partir do momento que a instituição coloca seus pacientes e familiares em um "pedestal”, há um sentimento de orgulho e satisfação em razão do valor que é conferido a eles. Os relatos positivos, portanto, funcionam como um cartão de visitas, elevando a credibilidade da instituição (Sammer et al., 2010). 